\title{
Desain Sistem Pemanenan Air Hujan Pada Rumah Hunian di Daerah Karst Kabupaten Malang
}

\section{Design of Rainwater Harvesting System for a Single House in Karst Region of Malang Regency}

\author{
L.R. Prihadi'), Anie Yulistyorini ${ }^{2 . a)}$ \& Mujiyono ${ }^{2)}$ \\ ${ }^{1)}$ Mahasiswa, Jurusan Teknik Sipil, Fakultas Teknik, Universitas Negeri Malang, Malang. \\ 2) Jurusan Teknik Sipil, Fakultas Teknik, Universitas Negeri Malang, Malang.
}

Koresponden : a)anie.yulistyorini.ft@um.ac.id.

\begin{abstract}
ABSTRAK
Penelitian ini dilakukan dengan memanfaatkan potensi air hujan sebagai sumber air minum pada musim kemarau. Dengan menggunakan metode Pemanenan Air Hujan, air hujan yang jatuh pada luasan atap rumah di tampung pada tangki dan selanjutnya air di filter untuk dijadikan air minum. Untuk mengetahui debit andalan periode 1 tahun dilakukan analisa berupa perhitungan curah hujan harian periode ulang 1 tahun dan menghitung kebutuhan air minum selama musim kemarau. Hasil analisa ini selanjutnya digunakan untuk menghitung kapasitas tangki yang sesuai dengan kebutuhan.Hujan rencana yang digunakan di dusun Mulyosari desa Donomulyo ini adalah kala ulang 1 tahun sebesar $177 \mathrm{~mm} /$ hari.

Model desain PAH ini digunakan untuk tipe rumah 54 yang berpenghuni 5 orang ini menghasilkan debit air $0,122 \mathrm{~m}^{3} /$ hari. Kebutuhan air minum selama musim kemarau sebesar $4,5 \mathrm{~m}^{3}$. Desain filter menggunakanperalatan pipa PVC yang diisi media filter berupa pasir silika, batu zeolit, karbon aktif, dan kapas filter aquarium. Hasil analisa laboratorium menunjukkan bahwa sistem PAH menghasilkan kualitas air hujan dengan $\mathrm{pH} 6,5$, kekeruhan 4,2 NTU, $\mathrm{Cl}^{-} 85,4 \mathrm{mg} / \mathrm{L}, \mathrm{NO}_{3}{ }^{-}<0,123 \mathrm{mg} / \mathrm{L}, \mathrm{SO}_{4}{ }^{2-}<0,230 \mathrm{mg} / \mathrm{L}$, $\mathrm{Mg}^{2+} 3 \mathrm{mg} / \mathrm{L}, \mathrm{CaCO}_{3} 12 \mathrm{mg} / \mathrm{L}$, dan $\mathrm{NH}_{3} 0,077 \mathrm{mg} / \mathrm{L}$. Dengan parameter tersebut air hasil sistem PAH yang berada diwilayah dusun Mulyosari tidak melebihi baku mutu dan memenuhi syarat sebagai air minum yang sesuai dengan standart baku mutu air minum pada PERMENKES\& PER/ IV/ nomor 492/ MENKES/ 2010.
\end{abstract}

Kata Kunci : manajemen fasilitas, filtrasi, kualitas air hujan, pemanenan air hujan

\section{PENDAHULUAN}

Milanovic (2004) menyebutkan bahwa karst adalah lahan yang terbentuk oleh pelarutan batuan gamping, dolomit, marmer, gipsum, dan batuan garam. Kawasan ini diperkirakan menutup $\pm 25 \%$ dari permukaan bumi. Proses pelarutan yang terjadi menyebabkan air permukaan dengan cepat meresap menuju sistem air bawah tanah akibat adanya retakanretakan serta lubang-lubang yang berukuran kecil, sedang maupun berukuran besar (White, 1988). Hal ini menyebabkan kondisi di permukaan tanah terlihat gersang dan berbatu (Cahyadi, 2010). Bila ditinjau dari sudut kimia, maka tanah karst berfungsi menetralkan kemasaman tanah. Namun dengan karakteristik karst, air yang masuk kedalam tanah tidak dapat tertampung karena sifat dan gradasi tanah karst tersebut (Maya, 2016).

Dusun Mulyosari di Desa Donomulyo Kecamatan Donomulyo Kabupaten Malang ini merupakan kawasan tanah kapur atau karst (BPS Kabupaten Malang, 2016). Dusun ini berada di ketinggian $\pm 480 \mathrm{~m}$ dpl yang merupakan daerah perbukitan dan dataran rendah yang 
berbatasan langsung dengan pantai selatan. Dengan melihat letak geografi dan keadaan tanah, Mulyosari merupakan salah satu wilayah yang sering mengalami krisis air pada musim kemarau.

Beberapa negara maju sudah menerapkan sistem Pemanenan Air Hujan (PAH), namun dengan model yang berbeda-beda. Di Brazil pemanfaatan air hujan ini menggunakan tangki yang di tanam pada tanah yaitu setengah bagian dari tangki, yang berfungsi agar rasa dan kadar air yang ditampung tidak terkontaminasi dengan zat lain. Di Thailand sistem PAH ini disimpan pada guci yang dapat menyimpan 100 liter air/guci, sistem ini digunakan pada wilayah yang mempunyai musim kemarau 6 bulan (UNEP, 2001). Di Indonesia juga sudah diterapkan sistem ini pada wilayah Gunung Kidul Jawa Tengah, sistem yang diaplikasikan dengan bak penampung terbuat dari beton yang dapat menyuplai kebutuhan air bersih masyarakat selama musim kemarau. Penampungan ini dirancang secara besar sesuai banyaknya rumah di wilayah tersebut (Danang, 2008).

Pada penelitian Wardiha (2013) rentang curah hujan di beberapa lokasi di Provinsi NTT tidak memenuhi syarat untuk pembangunan PAH. Hasil pengujian kualitas air tampungan PAH menunjukkan bahwa kualitas air dalam bak PAH tidak memenuhi syarat, baik untuk air bersih maupun air minum. Harsoyo ( 2010) melakukan penelitian tentang pemanfaatan PAH sebagai alternatif penyelamatan sumberdaya air di Jakarta, namun pada penelitiannya air yang dihasilkan PAH tidak terdapat uji kualitas air.

Di Dusun Mulyosari, air merupakan kebutuhan vital terutama di saat musim kemarau dimana dusun tersebut selalu mengalami kekeringan. Untuk mengatasi permasalahan tersebut, sistem PAH untuk tiap rumah sangat dibutuhkan untuk penyediaan air bersih di musim kemarau dengan mengolah dan menampung air hujan. Dalam rancangan desain PAH, penambahan filter sangat berperan penting untuk menghasilkan air bersih yang sesuai dengan kebutuhan dan memenuhi standart kualitas air minum yang telah tercantum dalam Permenkes tahun 2010.

Fasilitas ini harus dikelola sesuai dengan prinsip Manajemen Aset Fasilitas. Fasilitas harus dikelola dengan baik agar si fasilitas bisa selalu berfungsi dengan baik secara ekonomis, efisien dan efektif. Salah satu langkah pengelolaan fasilitas adalah perancangan Rancang Bangun Fasililtas yang baik (Soemitro \& Suprayitno 2018).

Untuk menghasilkan air bersih yang memenuhi persyaratan Permenkes tahun 2010, modifikasi filter air hujan di desain sesuai dengan kebutuhan tiap rumah di Dusun Mulyosari Kabupaten Malang. Sehingga masyarakat di dusun tersebut tidak mengalami kesulitan air bersih di musim kemarau.

\section{METODE}

Metode analisis yang digunakan pada penelitian ini adalah metode deskriptif kuantitatif. Metode ini berupa pengumpulan data, analisis data, dan interpretasi hasil analisis untuk mendapatkan informasi untuk pengambilan kesimpulan.

Analisa kualitas air dilakukan di laboratorium PT. Jasa Tirta I untuk mengukur konsentrasi beberapa parameter air hujan diantaranya adalah $\mathrm{pH}$, kekeruhan, $\mathrm{Cl}^{-}, \mathrm{NO}_{3}{ }^{-}, \mathrm{SO}_{4}{ }^{2-}$, $\mathrm{Mg}^{2+}, \mathrm{CaCO}_{3}$, dan $\mathrm{NH}_{3}$.

\section{Analisa Kebutuhan Air Minum}

Untuk menghitung kebutuhan air minum pada rumah tinggal digunakan standart SNI 03-7065-2005 untuk pemakaian kebutuhan air minum sesuai dengan jumlah penghuni dalam satu rumah. Untuk rumah tinggal tipe 54 spesifikasinya sebagai berikut:

1. Jenis bangunan : rumah tinggal

2. Lokasi : kawasan pemukiman Dusun Mulyosari, Desa

Donomulyo, Kabupaten Malang 
(e) ISSN 2615-1847 (p) ISSN 2615-1839

3. A (luas atap) : $54 \mathrm{~m}^{2}$

4. Jumlah penghuni : 5 org

Perhitungan kebutuhan air minum pada rumah tinggal diasumsikan rata-rata: 5 liter/org/hari (Roviq, 2013). Sehingga kebutuhan air minum per hari menjadi 25 liter/hari $\left(0,025 \mathrm{~m}^{3}\right)$.

\section{Perencanaan Pemanenan Air Hujan}

PAH di dusun Mulyosari merupakan salah satu cara alternatif untuk mengurangi permasalahan kekurangan air pada musim kemarau. Pada sistem PAH ini terdapat 4 bagian, yaitu area tangkapan air hujan, bak penampung air hujan, alat filtrasi, dan bak penampungan air siap pakai.Perhitungan PAH disesuaikan dengan jumlah kebutuhan air dalam satu rumah. Dalam bentuknya pengumpulan air hujan dari atas atap rumah dilakukan dengan cara menempatkan talang tepat dibawah ujung bawah genting. Penempatan talang diatur sehingga air hujan yang berasal dari atap rumah dapat mengalir melalui talang menuju tangki penampungan air hujan yang diletakan dibagian bawah salah satu ujung talang. Untuk tahap selanjutnya air akan di treatment pada alat filtrasi dengan dua kali tahapan filtrasi. Hasil filtrasi akan dialirkan menuju bak penampungan air siap pakai.

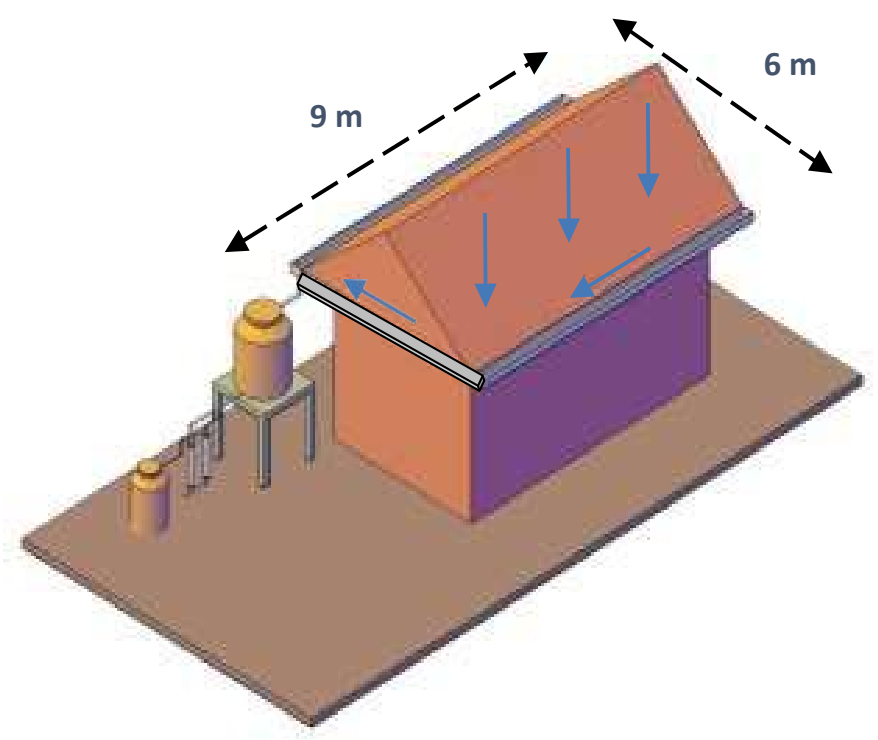

Gambar 1. Desain Sistem Pemanenan Air Hujan

\section{Bak Penampungan Air Hujan}

Bak penampungan atau tangki digunakan sebagai tempat penampungan air hujan hasil tangkapan dari atap. Tangki diletakan di tempat yang cukup tinggi yang bertujuan untuk menghasilkan tekanan air yang cukup besar. Tangki dapat di letakan diatas bangunan beton, rangkaian besi ataupun kayu dengan struktur yang kuat agar dapat menahan beban tangki dan air yang ada di dalamnya. Pada penelitian ini tangki yang digunakan adalah tangki fibber dengan kapasitas $4 \mathrm{~m}^{3}$.

\section{Alat Filtrasi}

Model filter disesuaikan dengan kebutuhan, perancangan filter yang dibuat untuk menjernihkan air, mengurangi kadar logam, dan menyerap bahan kimia yang terlarut di dalam air. Tabung filter yang digunakan adalah pipa PVC, dan media yang digunakan sebagai filter adalah pasir silika, batu zeolit, karbon aktif, dan kapas filter aquarium (Prawita \& Hadi, 2014). 
Alat filtrasi yang direncanakan menggunakan media pipa PVC dengan ukuran 3" untuk media penyaringan dan ukuran $3 / 4$ " untuk media pengaliran air. Pada alat filtrasi dilengkapi dengan stop kran, pipa sock drad luar dan dalam, pipa knee, pipa t, tutup pvc (dop), TBA, dan lem pvc.

Pada media filter terdapat beberapa material penyusun diataranya adalah kapas filter aquarium, karbon aktif, batu zeolit, dan pasir silika. Susunan yang paling bawah adalah pasir silika dengan ketebalan $10 \mathrm{~cm}$ dan dengan ukuran diameter 0,1-0,2 $\mathrm{mm}$, pasir silika ini memiliki partikel yang sangat kecil sehingga dapat digunakan untuk menyaring kotoran pada air(Haminal, 2013). Berikutnya adalah kapas filter aquarium dengan ketebalan $10 \mathrm{~cm}$, kapas ini berguna untuk menyaring kotoran yang ada dalam air. Lapisan kapas filter aquarium pada perencanaan filter ini berada diantara lapisan pasir silika dan batu zeolit, lapisan batu zeolit dan karbon aktif, dan lapisan terakhir pada bagian atas susunan media filter.

Lapisan selanjutnya adalah batu zeolit dengan ketebalan $10 \mathrm{~cm}$ dengan ukuran $\pm 1-4 \mathrm{~cm}$, batu zeolit berguna untuk menghilangkan polutan kimia yang terkandung dalam air (Untari, 2015). Kemudian terdapat lapisan karbon aktif dengan ketebalan $10 \mathrm{~cm}$ dan dengan ukuran 0,5-2 cm, karbon aktif ini berguna dalam penjernihan air dan menghilangkan senyawasenyawa organik dalam air(Suharto, 2011). Dengan beberapa susunan material diatas dapat mempengaruhi kualitas air yang dihasilkan. Untuk treatment pada material pasir silika, batu zeolit, dan karbon aktif membutuhkan proses pembersihan yang dilakukan sampai beberapa kali sampai material bersih dari partikel pengotor.

Skema aliran air pada media filtrasi ini dimulai dari air masuk melalui pintu inlet kemudian stop kran 1 dibuka dan stop kran 2 ditutup. Selanjutnya air mengair kedalam filter kemudian mengalir dengan sistem upflow. Untuk stop kran 4 dan 5 dalam posisi tertutup. Dari tabung filter 1, air mengalir masuk ke dalam tabung filter 2 dan selanjutnya mengalir melewati media filter 2 untuk proses terakhir. Kemudian kran 3 dibuka dan air mengalir keluar dari pintu outflow.

(a)

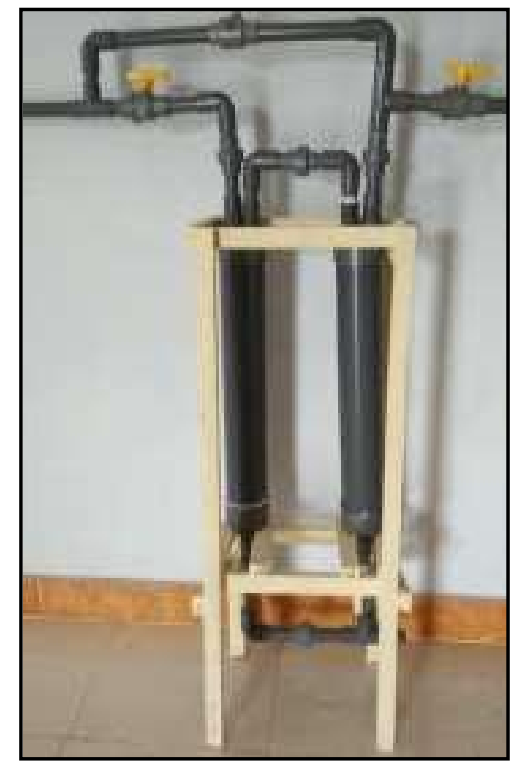

(b)

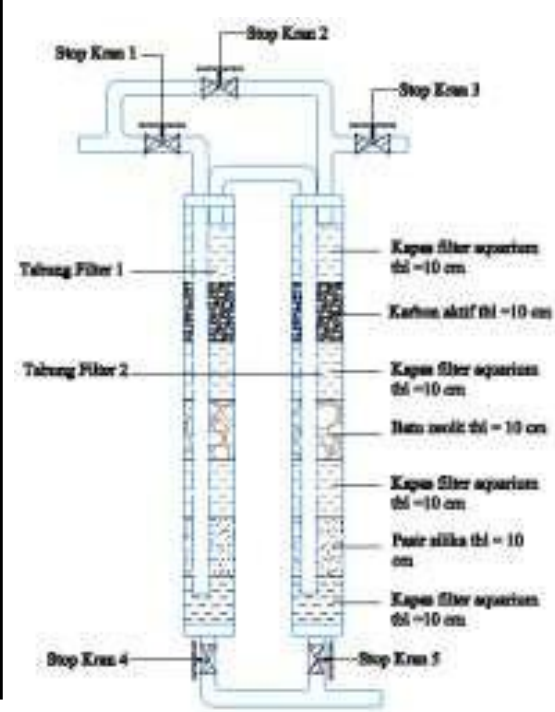

(c)

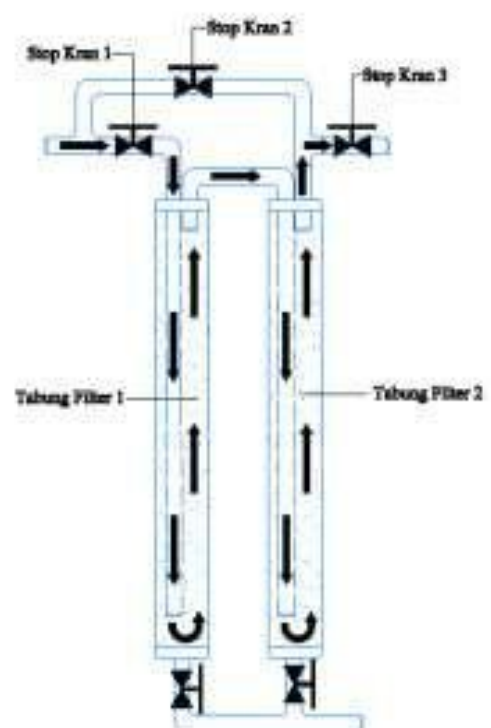

Gambar 2. (a) Rancangan Desain Filtrasi, (b) Susunan Media Filtrasi, (c) Aliran Air Pada Filtrasi

Pencucian dilakukan dengan cara membalik arah aliran air yang masuk ke dalam tabung. Untuk pembersihan tabung filter 2 air bersih dialirkan dari pintu inlet kemudian stop kran 1 dan 3 ditutup. Untuk stop kran 2 dibuka, kemudian air mengalir masuk 
filter 2. Air mengalir melewati susunan media filter dari atas ke bawah selanjutnya stop kran 5 dibuka kemudian air kotor hasil back wash keluar melewati pintu outlet. Sedangkan untuk pembersihan tabung filter 1 dengan cara mengalirkan air bersih dari pintu inlet kemudian stop kran 1 dan 3 ditutup. Stop kran 2 dibuka, kemudian air mengalir masuk kedalam tabung filter 2. Air mengalir pada lapisan media filter dari atas ke bawah, selanjutnya dengan posisi stop kran 5 tertutup.Tahap berikutnya air mengalir naik pada pipa dan masuk kedalam tabung filter 1. Dalam tabung filter 1 air mengalir kebawah untuk proses pembersihan material filter selanjutnya stop kran 4 dibuka dan air kotor hasil back wash keluar melewati pintu outlet.

(a)

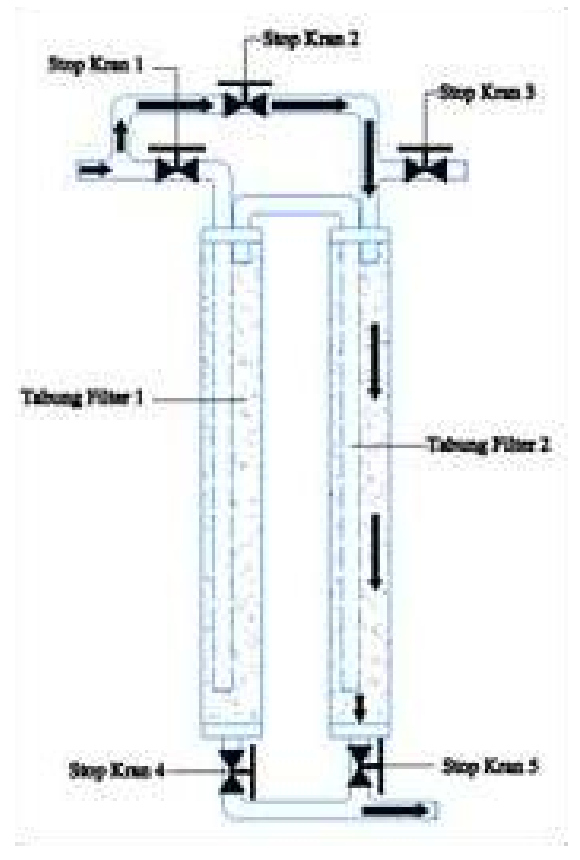

(b)

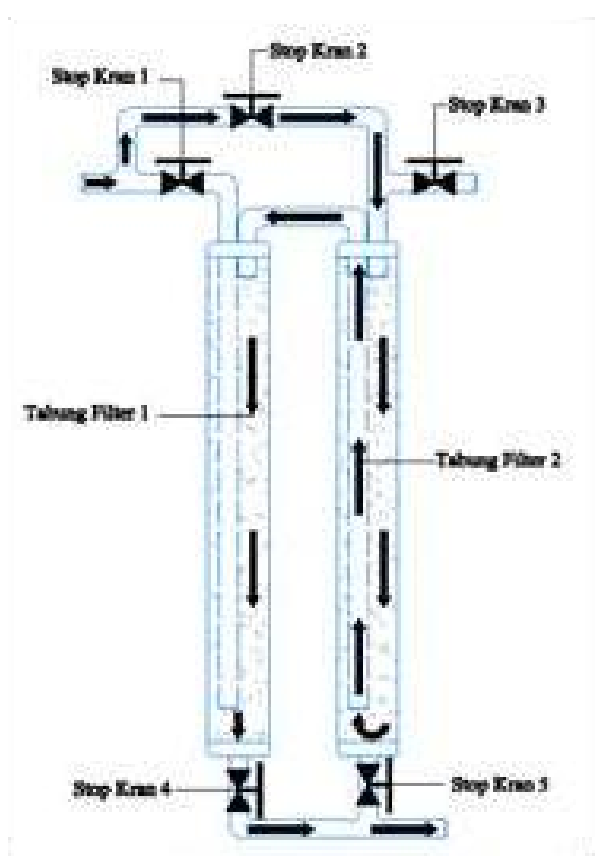

Gambar 3. (a) Aliran Air Pembersihan Tabung 2, (b) Aliran Air Pembersihan Tabung 1

\section{HASIL DAN PEMBAHASAN}

\section{Data Curah Hujan}

Data curah hujan di wilayah dusun Mulyosari diperoleh melalui data sekunder dari Dinas PU SDA Kabupaten Malang yang diambil dari stasiun wilayah Donomulyo. Berikut adalah data curah hujan stasiun Donomulyo yang berupa curah hujan bulanan dengan menggunakan metode rata-rata pada periode 5 tahun terakhir yaitu dari tahun $2012-2016$. 
Tabel 1. Data Curah Hujan

\begin{tabular}{cccccc}
\hline Tahun & $\mathbf{2 0 1 2}$ & $\mathbf{2 0 1 3}$ & $\mathbf{2 0 1 4}$ & $\mathbf{2 0 1 5}$ & $\mathbf{2 0 1 6}$ \\
\hline Januari & 440 & 534 & 607 & 302 & 292 \\
Februari & 95 & 137 & 35 & 350 & 516 \\
Maret & 553 & 145 & 102 & 176 & 188 \\
April & 44 & 201 & 162 & 226 & 169 \\
Mei & 75 & 98 & 43 & 130 & 217 \\
Juni & 0 & 267 & 18 & 0 & 192 \\
Juli & 52 & 147 & 78 & 0 & 140 \\
Agustus & 0 & 13 & 27 & 0 & 126 \\
September & 31 & 0 & 0 & 0 & 331 \\
Oktober & 38 & 77 & 0 & 0 & 352 \\
November & 87 & 172 & 0 & 64 & 400 \\
Desember & 410 & 741 & 278 & 383 & 561 \\
Max & 553 & 741 & 607 & 383 & 561 \\
\hline Jumlah & 1825 & 2532 & 1350 & 1631 & 3484 \\
\hline
\end{tabular}

Sumber: Dinas PU SDA Kabupaten Malang

\section{Perhitungan Potensi Suplai Air Hujan}

Untuk perhitungan suplai air hujan, diperlukan perhitungan hujan andalan. Perhitungan hujan andalan dilakukan melalui pengolahan data curah hujan bulanan yang ada dengan mengurutkan peringkat data curah hujan berdasarkan besar curah hujan rata-rata bulanan. Probabilitas hujan andalan dapat dihitung menggunakan rumus :

$$
P(\%)=\frac{m}{(m+1)} \times 100 \%
$$

Dimana :

$$
\begin{array}{ll}
\mathrm{P} & =\text { Probabilitas (\%) } \\
\mathrm{m} & =\text { Nomor urut data } \\
\text { debit } \mathrm{n} & =\text { Jumlah data debit }
\end{array}
$$

Untuk perhitungan probabilitas terjadinya hujan andalan urutan nomor 1 sebagai berikut :

$$
\begin{aligned}
& P(\%)=\frac{1}{(5+1)} \times 100 \% \\
& P(\%)=16,67 \%
\end{aligned}
$$

\begin{tabular}{|c|c|c|c|c|c|}
\hline \multirow{2}{*}{ Tahun } & \multirow{2}{*}{$\begin{array}{c}\text { Curah Hujan } \\
\text { (mm/tahun) }\end{array}$} & \multicolumn{3}{|c|}{ Urutan } & \multirow{2}{*}{$\begin{array}{c}\text { Andalan } \\
(\%)\end{array}$} \\
\hline & & No & Tahun & Curah Hujan & \\
\hline 1 & 2 & 3 & 4 & 5 & 6 \\
\hline 2012 & 1825 & 1 & 2016 & 3484 & 16.67 \\
\hline 2013 & 2532 & 2 & 2013 & 2532 & 33.33 \\
\hline 2014 & 1855 & 3 & 2014 & 1855 & 50.00 \\
\hline 2015 & 1631 & 4 & 2012 & 1825 & 66.67 \\
\hline 2016 & 3484 & 5 & 2015 & 1631 & 83.33 \\
\hline
\end{tabular}

Perhitungan probabilitas hujan andalan selanjutnya dapat dilihat pada Tabel 2.

Tabel 2. Probabilitas Hujan Andalan

Pada tabel 2. di atas dapat ditentukan curah hujan andalan secara langsung dengan memilih data hujan dengan probabilitas diatas $80 \%$ yang berada pada tahun 2015 yaitu sebesar 83,3\%.Dari data curah hujan andalan dapat dilihat fluktuasi curha hujan seperti grafik berikut : 
(e) ISSN 2615-1847 (p) ISSN 2615-1839

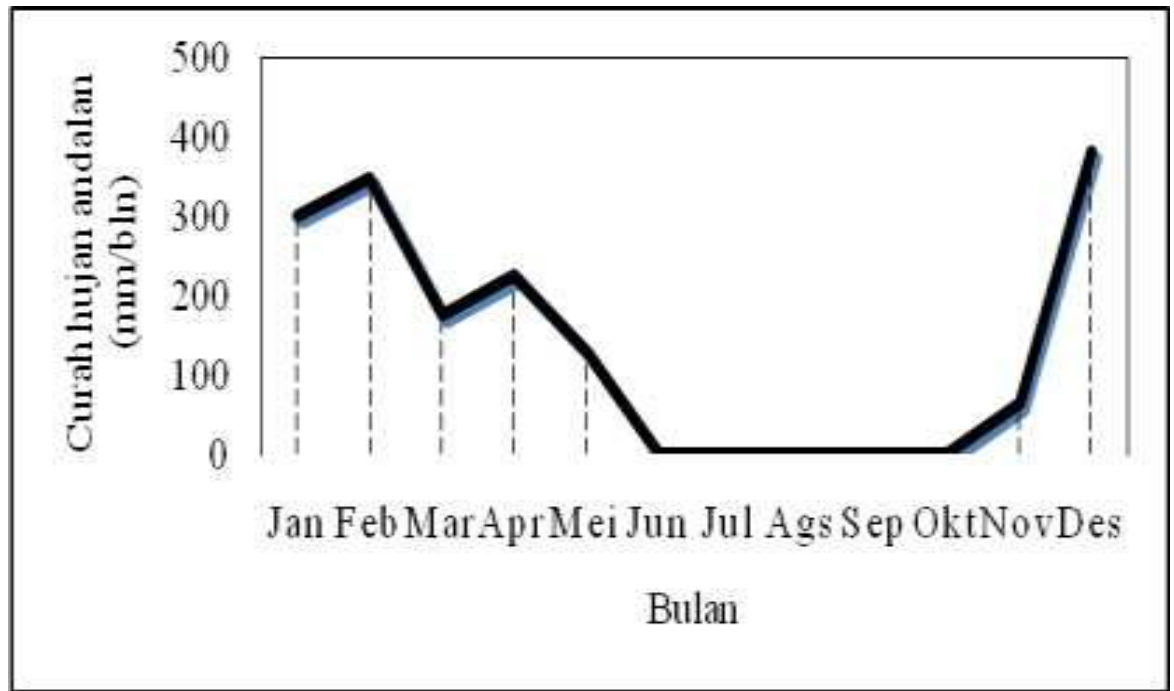

Gambar 4. Curah Hujan Andalan

Dari grafik dapat dilihat adanya kekurangan air pada saat bulan kering. Dimana curah hujan yang terjadi sangat kecil yaitu $<50 \mathrm{~mm} /$ bulan pada bulan Juni, Juli, Agustus, September, dan Oktober.

Dari data curah hujan andalan dapat dihitung volume suplai air hujan yang dapat ditampung untuk setiap bulannya. Berikut contoh perhitungan volume ketersediaan air hujan untuk suplai bulan Januari:

Luas atap (A) rumah : $54 \mathrm{~m}^{2}$

Koefisien run off $(\mathrm{C}): 0,9$

$$
V=R \times A \times C
$$

$V=\left(302 \times 10^{-3} \times 54 \times 0,9\right.$

$V=14,68 \mathrm{~m}^{3} /$ bulan

Dimana: $\mathrm{R}=$ Hujan andalan $(\mathrm{mm}) \mathrm{A}=$ Luas atap rumah $\left(\mathrm{m}^{2}\right) \mathrm{C}=$ Koefisien run off

Volume ketersediaan air hujan untuk bulan Febuari sampai dengan Desember dapat dilihat pada Tabel 3. sebagai berikut. 
Tabel 3. Potensi Volume Suplai Air Hujan

\begin{tabular}{cccc}
\hline Bulan & $\begin{array}{c}\text { Hujan Andalan } \\
(\mathbf{m m})\end{array}$ & $\begin{array}{c}\text { Luas Atap } \\
\left(\mathbf{m}^{\mathbf{2}}\right)\end{array}$ & $\begin{array}{c}\text { Volume Air } \\
\text { Hujan }\end{array}$ \\
\hline $\mathbf{1}$ & $\mathbf{2}$ & $\mathbf{3}$ & $\mathbf{4 = ( \mathbf { 2 x 3 x C } )}$ \\
\hline Januari & 302 & 54 & 14.68 \\
Februari & 350 & 54 & 17.01 \\
Maret & 176 & 54 & 8.55 \\
April & 226 & 54 & 10.98 \\
Mei & 130 & 54 & 6.32 \\
Juni & 0 & 54 & 0 \\
Juli & 0 & 54 & 0 \\
Agustus & 0 & 54 & 0 \\
September & 0 & 54 & 0 \\
Oktober & 0 & 54 & 0 \\
Nopember & 64 & 54 & 3.11 \\
Desember & 383 & 54 & 18.61 \\
Jumlah & $\mathbf{1 6 3 1}$ & & $\mathbf{7 9 . 2 6}$ \\
\hline
\end{tabular}

\section{Perhitungan Metode Pemenuhan Kebutuhan Air}

Metode pemenuhan kebutuhan air dilakukan dengan cara mengatur kapasitas tangki PAH. Penentuan volume tangki ini menggunakan metode neraca air yaitu menyesuaikan dengan kondisi musim hujan dan kemarau. Sehingga air yang dapat disuplai pada musim penghujan dapat memenuhi kebutuhan air pada musim kemarau yang menjadikan neraca air tersebut seimbang. Berikut perhitungan pemenuhan air pada setiap bulan.

Tabel 4. Perhitungan Pemenuhan Kebutuhan Air

\begin{tabular}{|c|c|c|c|c|c|c|c|}
\hline Bulan & $\begin{array}{c}\text { Jumlah } \\
\text { Hari }\end{array}$ & $\begin{array}{c}\text { Hujan } \\
\text { Andalan } \\
\text { (mm) }\end{array}$ & $\begin{array}{c}\text { Luas Atap } \\
\qquad\left(\mathrm{m}^{2}\right)\end{array}$ & $\begin{array}{c}\text { Suplai Air } \\
\begin{array}{c}\text { Hujan } \\
\left(\mathbf{m}^{3}\right)\end{array} \\
\end{array}$ & $\begin{array}{c}\text { Kebutuha } \\
\text { n } \\
\text { Air }\left(\mathbf{m}^{3}\right)\end{array}$ & $\begin{array}{c}\text { Kekurangan } \\
\text { Air }\left(\mathbf{m}^{3}\right)\end{array}$ & $\begin{array}{l}\text { Kelebihan } \\
\text { Air }\left(\mathbf{m}^{3}\right)\end{array}$ \\
\hline 1 & 2 & 3 & 4 & $5=(3 \times 4 \times C)$ & 6 & $7=(6-5)$ & $8=(5-6)$ \\
\hline Januari & 31 & 302 & 54 & 14.68 & 0.78 & - & 13.9 \\
\hline Februari & 28 & 350 & 54 & 17.01 & 0.7 & - & 16.31 \\
\hline Maret & 31 & 176 & 54 & 8.55 & 0.78 & - & 7.77 \\
\hline April & 30 & 226 & 54 & 10.98 & 0.75 & - & 10.23 \\
\hline Mei & 31 & 130 & 54 & 6.32 & 0.78 & - & 5.54 \\
\hline Juni & 30 & 0 & 54 & 0 & 0.75 & 0.75 & - \\
\hline Juli & 31 & 0 & 54 & 0 & 0.78 & 0.78 & - \\
\hline Agustus & 31 & 0 & 54 & 0 & 0.78 & 0.78 & - \\
\hline September & 30 & 0 & 54 & 0 & 0.75 & 0.75 & - \\
\hline Oktober & 31 & 0 & 54 & 0 & 0.78 & 0.78 & - \\
\hline Nopember & 30 & 64 & 54 & 3.11 & 0.75 & - & 2.36 \\
\hline Desember & 31 & 383 & 54 & 18.61 & 0.78 & - & 17.83 \\
\hline Jumlah & & 1631 & & 79.26 & 9.16 & 3.84 & 73.94 \\
\hline
\end{tabular}


(e) ISSN 2615-1847 (p) ISSN 2615-1839

Cek hasil perhitungan:

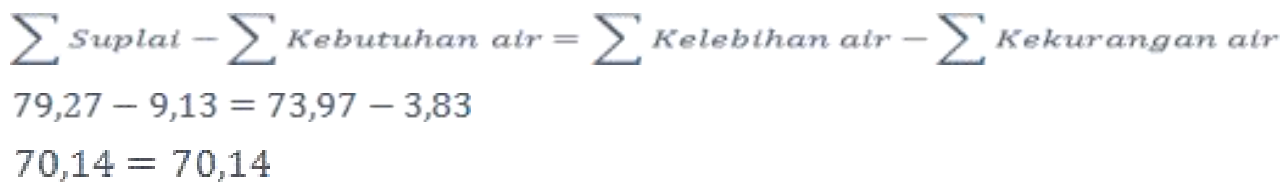

\section{Perhitungan Volume Tangki PAH}

Kapasitas tangki PAH yang direncanakan adalah jumlah volume kekurangan air yang terdapat pada Tabel 4, ¿ Kekurangan air $=3,83 \sim 4 \mathrm{~m}^{3}$.

Berdasarkan perhitunngan kapasitas tangki PAH dapat dilakukan perhitungan neraca air untuk mengetahui volume air hujan yang digunakan setiap bulannya. Berikut contoh perhitungan neraca air pada bulan November dan Desember:

\section{November}

$$
\begin{aligned}
& \text { V. Suplai air } \quad: 3,11 \mathrm{~m}^{3} \\
& \text { Kebutuhan air } \quad: 0,75 \mathrm{~m}^{3} \\
& \text { Kapasitas tangki : } 4 \mathrm{~m}^{3} \\
& \text { V. Tangki : Suplai }- \text { Kebutuhan }+ \text { V. Sebelumnya } \\
& \text { V. Suplai air }: 3,11-0,75+0 \\
& \text { : } 2,36 \mathrm{~m}^{3} \\
& \text { : } 2,36-4 \\
& \text { : }-1,64 \mathrm{~m}^{3} \text { (tidak melebihi kapasitas) }
\end{aligned}
$$

\section{Desember}

$$
\begin{aligned}
& \text { V. Suplai air } \quad: 18,61 \mathrm{~m}^{3} \\
& \text { Kebutuhan air } \quad: 0,78 \mathrm{~m}^{3} \text { Kapasitas tangki }: 4 \mathrm{~m}^{3} \\
& \begin{aligned}
\text { V. Tangki : Suplai }- \text { Kebutuhan }+ \text { V. Sebelumnya } \\
:
\end{aligned} \\
& \quad: 20,61-0,78+2,36 \\
&
\end{aligned}
$$

V. Terbuang : V. Tangki - Kapasitas tangki

$$
\begin{aligned}
& : 20,20-4 \\
& : 16,20 \mathrm{~m}^{3} \text { (melebihi kapasitas) }
\end{aligned}
$$

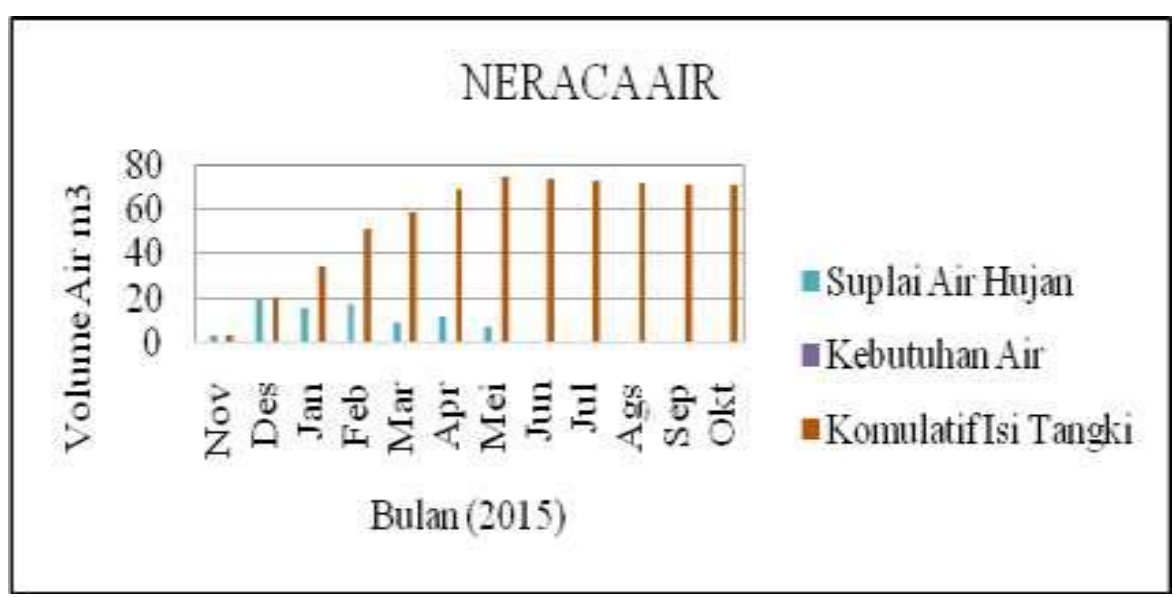

Gambar 5. Neraca Air

\section{Intensitas Hujan}

Dalam menghitung intensitas hujan yang dipakai adalah curah hujan pada bulan Desember tahun 2016. Untuk perhitungantatau waktu konsentrasi menggunakan rumus 
Kirpich. Kemudian untuk perhitungan intensitas air menggunakan rumus Monobe, perhitungan sebagai berikut:

a. $\mathrm{R}_{24}=177 \mathrm{~mm} / \mathrm{hari}$

b. $\mathrm{L}=9 \mathrm{~m}$

c. $\mathrm{S}=$ sudut kemiringan $45=4,23 \mathrm{~m}$

$$
\begin{aligned}
& t_{c}=\frac{0,87 \times L^{2^{0,385}}}{1000 \times S} \\
& t_{c}=\frac{0,87 \times 9^{2}}{1000 \times 4,23} \\
& t_{e}=0,207
\end{aligned}
$$

Dari rumus Kirpich diatas nilai Tc telah didapatkan kemudian untuk perhitungan intensitas hujan sebagai berikut :

$$
\begin{aligned}
& I=\frac{R_{24}}{24} \times \frac{24^{\frac{2}{3}}}{t_{e}} \\
& I=\frac{52,07}{24} \times \frac{24}{0,207} \\
& I=90,18 \mathrm{~mm} / \text { harl }^{\frac{2}{3}}
\end{aligned}
$$

\section{Debit Hujan}

Untuk perhitungan selanjutnya menggunakan Metode Rasional untuk menghitung debit dengan daerah pengaliran yang terbatas. Perhitungan sebagai berikut:

a. $A=54 \mathrm{~m}^{2}=0,0054$ ha

b. $\mathrm{C}=0,9$ pada rumah tangga (Tabel 2.2)

$$
\begin{aligned}
& Q=\frac{1}{3,6} \times C \times I \times A \\
& Q=\frac{1}{36} \times 0,9 \times 90,18 \times 0,0054 \\
& Q=0,122 \mathrm{~m}^{3} / \text { hari } \\
& \text { Dimana: } \\
& Q \quad=\text { debit air hujan }\left(\mathrm{m}^{3} / \text { hari }\right) \\
& \text { C }=\text { coefisien run off } \\
& \text { I } \quad \text { intensitas air hujan }(\mathrm{mm} / \text { hari }) \\
& \text { A } \quad=\text { luas atap }\left(\mathrm{m}^{2}\right)
\end{aligned}
$$

\section{Hasil Uji Kualitas Air}

Beberapa persyaratan standard air bersih untuk kuantitas dan kualitas harus mengacu pada standard ideal. Badan internasional PBB mengeluarkan standard secara umum dan beberapa negara juga mengeluarkan standard masing-masing yang disesuaikan dengan kondisi masyarakatnya, termasuk Indonesia. Indonesia menggunakan PERMENKES RI nomor 492/MENKES/PER/IV/20 untuk mengetahui karakteristik air. 
(e) ISSN 2615-1847 (p) ISSN 2615-1839

Jurnal Manajemen Aset Infrastruktur \& Fasilitas - Vol. 3, No. 1, Maret 2019

Tabel 5. Hasil Pengujian Kualitas Air dan Standart Baku Mutu

\begin{tabular}{|c|c|c|c|c|}
\hline No & Parameter & $\begin{array}{c}\text { Hasil } \\
\text { Penelitian } \\
\text { Awal }\end{array}$ & $\begin{array}{c}\text { Hasil } \\
\text { Penelitian } \\
\text { PAH }\end{array}$ & $\begin{array}{c}\text { Kadar Maksimum } \\
\text { yang } \\
\text { Diperbolehkan }\end{array}$ \\
\hline 1 & $\mathrm{pH}$ & 7,5 & $\overline{6,5}$ & $6,5-8,5$ \\
\hline 2 & Kekeruhan & $0,35 \mathrm{NTU}$ & 4,2 NTU & $5 \mathrm{NTU}$ \\
\hline 3 & Klorida $\left(\mathrm{Cl}^{-}\right)$ & $5,0 \mathrm{mg} / \mathrm{L}$ & $85,4 \mathrm{mg} / \mathrm{L}$ & $250 \mathrm{mg} / \mathrm{L}$ \\
\hline 4 & Nitrat (NO3 ${ }^{-}$) & $1,973 \mathrm{mg} / \mathrm{L}$ & $<0,123 \mathrm{mg} / \mathrm{L}$ & $50 \mathrm{mg} / \mathrm{L}$ \\
\hline 5 & Sulfat $\left(\mathrm{SO}^{L^{-}}{ }^{-}\right)$ & $<0,230 \mathrm{mg} / \mathrm{L}$ & $<0,230 \mathrm{mg} / \mathrm{L}$ & $250 \mathrm{mg} / \mathrm{L}$ \\
\hline 6 & Magnesium $\left(\mathrm{Mg}^{2+}\right)$ & $0,574 \mathrm{mg} / \mathrm{L}$ & $3 \mathrm{mg} / \mathrm{L}$ & - \\
\hline 7 & $\begin{array}{l}\text { Kesadahan Total } \\
(\mathrm{CaCO} 3)\end{array}$ & $61 \mathrm{mg} / \mathrm{L}$ & $12 \mathrm{mg} / \mathrm{L}$ & $500 \mathrm{mg} / \mathrm{L}$ \\
\hline 8 & Amonia (NH3) & $0,078 \mathrm{mg} / \mathrm{L}$ & $0,077 \mathrm{mg} / \mathrm{L}$ & $1,5 \mathrm{mg} / \mathrm{L}$ \\
\hline 9 & $\operatorname{Besi}(\mathrm{Fe})$ & Tidak Terdeteksi & & $0,3 \mathrm{mg} / \mathrm{L}$ \\
\hline
\end{tabular}

Pada penelitian (Untari, 2015) terdapat parameter yang tidak terdeteksi pada air huan yaitu Sianida, Krom, Kadmium, Raksa, Mangan, Timbal, Selenium, dan Seng. Maka pada penelitian ini menggunakan 9 parameter yang kemungkinan terkandung dalam air hujan digunakan sebagai acuan air hujan tersebut masuk dalam prasyarat air minum atau tidak. Parameter tersebut adalah $\mathrm{pH}$, Kekeruhan, Klorida $\left(\mathrm{Cl}^{-}\right)$, Nitrat $\left(\mathrm{NO}_{3}^{-}\right)$, Sulfat $\left(\mathrm{SO}_{4}{ }^{2-}\right)$, Magnesium $\left(\mathrm{Mg}^{2+}\right)$, Kesadahan Total $\left(\mathrm{CaCO}_{3}\right)$, Amonia $\left(\mathrm{NH}_{3}\right)$, Besi (Fe).Nilai pH suatu perairan mencirikan keseimbangan antara asam dan basa dalam air dan merupakan pengukuran konsentrasi ion hidrogen dalam larutan. Pembatasan $\mathrm{pH}$ dilakukan karena akan mempengaruhi rasa, korosifitas air dan efisiensi klorinasi(Hanum, 2002). Pada hasil pengujian diatas nilai $\mathrm{pH}$ sebelum melewati sistem PAH sebesar 7,5 namun hasil pengujian air setelah terdapat PAH turun menjadi 6,5. Hal ini disebabkan adanya perbedaan waktu pengambilan sampel air hujan sehingga berpengaruh pada $\mathrm{pH}$. Namun $\mathrm{pH}$ masih layak dijadikan air minum karena kadar maksimum yang diperbolehkan sebesar 6,5-8,5. pH yang lebih kecil dari 6,5 menimbulkan rasa tidak enak dan dapat menyebabkan korosifitas pada pipa-pipa air dan menyebabkan beberapa bahan kimia berubah menjadi racun sehingga mengganggu kesehatan (Waluyo, 2005).

Hasil laboratorium nilai kekeruhan sebesar 4,2 NTU yang sebelumnya hanya 0,35 NTU yang mendekati ambang batas sebesar 5 NTU meskipun sudah dilakukan treatment menggunakan karbon aktif. Dari hasil percobaan dan analisa di laboratorium hal seperti ini merupakan kejadian yang tidak diharapkan karena hasil yang bertambah nilai kekeruhannya. Peran media zeolit yang mampu mengadsorpsi dan menyaring molekul organik yang larut dan koloid yang menyebabkan air keruh. Dikarenakan struktur zeolit berongga serta karbon aktif membentuk amorf yang sebagian besar terdiri dari karbon bebas dan memiliki permukaan berrongga menyebabkan karbon aktif dapat mengadsorpsi gas dan senyawa-senyawa terlarut (Untari, 2015). Klorida $\left(\mathrm{Cl}^{-}\right)$pada pengujian ini sebesar $5 \mathrm{mg} / \mathrm{l}$ namun setelah melewati sistem PAH naik menjadi $85,4 \mathrm{mg} / \mathrm{l}$. Nilai Klorida dapat berubah-ubah disebabkan dari adanya perbedaan karakteristik hujan yang dipengaruhi oleh siklus hidrologi itu sendiri. Klorida dalam konsentrasi diatas $250 \mathrm{mg} / \mathrm{l}$ menimbulkan rasa yang berbeda dalam air. Bila berikatan dengan ion natrium dapat menyebabkan rasa asin dan dapat merusak pipa-pipa air (Waluyo, 2005).

Nitrat adalah senyawa yang paling sering ditemukan di dalam air bawah tanah maupun air yang terdapat dipermukaan. Pencemaran oleh pupuk nitrogen, termasuk amonia anhidrat seperti juga sampah organik hewan maupun manusia, dapat meningkatkan kadar nitrat di dalam air(Harry, 2006). Nitrat pada sampel air yang tidak terlalu besar yaitu sebesar $1,973 \mathrm{mg} / \mathrm{l}$ menjadi $<0,123 \mathrm{mg} / \mathrm{l}$, dikarenakan berasal dari proses alami dalam siklus hidrologi yaitu melalui proses nitrifikasi. 
Dengan kadar nitrat yang tidak terlalu besar tersebut tidak membawa dampak kesehatan yang buruk. Pengujian pada air hujan memiliki nilai Sulfat $<0,230 \mathrm{mg} / \mathrm{L}$. Dan pada pengujian air dengan metode PAH air yang dihasilkan nilai Sulfat $<0,230 \mathrm{mg} / \mathrm{L}$. Sulfat tidak mengalami penurunan ataupun kenaikan. Dan layak dikonsumsi sebagai air minum karena di bawah kadar maksimum sebesar $250 \mathrm{mg} / \mathrm{l}$. Adanya Sulfat berasal dari oksidasi gas $\mathrm{SO}_{2}$ akibat pencemaran udara juga memberikan kontribusi terdapatnya sulfat dalam bak penampungan air hujan. Hasil pengujian senyawa sulfat (SO4 ) dalam jumlah besar dapat bereaksi dengan ion natrium atau magnesium dalam air sehingga membentuk garam yang dapat menimbulkan iritasi gastrointestinal disamping juga dapat menyebabkan dehidrasi (Waluyo, 2005).

Kesadahan $\left(\mathrm{CaCO}_{3}\right)$ terutama disebabkan oleh adanya kalsium $(\mathrm{Ca})$ dan magnesium $(\mathrm{Mg})$ sebab umumnya tanah karst memiliki komposisi mineral batuan karbonat yang memang didominasi $\mathrm{Ca}$ dan $\mathrm{Mg}$, sesuai dengan kondisi di dusun Mulyosari yang termasuk daerah perbukitan kapur. Hasil uji Kesadahan $\left(\mathrm{CaCO}_{3}\right)$ sebesar $61 \mathrm{mg} / \mathrm{L}$ dan pada pengujian air dengan metode PAH air yang dihasilkan nilai kesadahan $12 \mathrm{mg} / \mathrm{Lmasih}$ dapat dipergunakan untuk air dengan batas maksimum $500 \mathrm{mg} / \mathrm{l}$. Kesadahan menyebabkan adanya endapan putih kalsium bikarbonat pada tempat pendidihan air(Achmad, 2004).Untuk hasil pengujian awal pada air hujan memiliki nilai Besi (Fe) tidak terdeteksi. Sehingga pada pengujian air dengan metode PAH parameter Besi tidak diujikan. Besi dalam endapan yang mengakibatkan kekeruhan dalam air bersih sehingga dapat menimbulkan berbagai gangguan menurut (Wahid, 2006).

\section{KESIMPULAN}

Sistem pemanenan air hujan di wilayah yang mengalami kekurangan air menjadi alternative untuk pemenuhan kebutuhan air bersih di masyarakat. Sistem ini dapat diapliaksikan pada setiap rumah untuk menyediakan air bersih ketika musim kemarau. Berdasarkan uraian di atas, beberapa temuan hasil studi diuraikan pada beberapa poin dibawah ini :

1. Hujan rencana yang digunakan pada wilayah Mulyosari, kala ulang 1 tahun sebesar 177 $\mathrm{mm} /$ hari, dengan tipe rumah 54 menghasilkan debit air $0,122 \mathrm{~m}^{3} /$ hari.

2. Kebutuhan air minum selama musim kemarau dalam rumah type 54 dengan anggota keluarga berjumlah 5 orang sebesar $4,5 \mathrm{~m}^{3}$.

3. Kapasitas tangki dalam musim kemarau selama 6 bulan yang dibutuhkan sebesar $4 \mathrm{~m}^{3}$. Kelebihan air sebesar $618,04 \mathrm{~m}^{3}$, kelebihan tersebut akan mengalir secara otomatis pada drainase yang kemudian masuk kedalam sumur resapan.

4. Desain filter menggunakan pipa PVC, stop kran, knee t, lem dan dop penutup. Untuk material filter berupa pasir silika, batu zeolit, karbon aktif, dan kapas filter aquarium.

5. Hasil laboratorium Jasa Tirta 1, kualitas air hujan setelah menggunakan sistem PAH adalah $\mathrm{pH}(6,5)$, Kekeruhan $(4,2 \mathrm{NTU})$, Klorida $(85,4 \mathrm{mg} / \mathrm{L})$, Nitrat $(<0,123 \mathrm{mg} / \mathrm{L})$, Sulfat $(<0,230 \mathrm{mg} / \mathrm{L})$, Magnesium (3 mg/L), Kesadahan Total $(12 \mathrm{mg} / \mathrm{L})$, Amonia $(0,077$ $\mathrm{mg} / \mathrm{L}$ ), Besi (Ttd). Dengan parameter tersebut air hasil sistem PAH yang berada diwilayah dusun Mulyosari memenuhi syarat sebagai air minum sesuai dengan standart baku mutu air minum pada PERMENKES \& PER/ IV/ nomor 492/ MENKES/, 2010.

\section{DAFTAR PUSTAKA}

Achmad, R. (2004). Kimia Lingkungan. Teknik Lingkungan, Universitas Negeri Jakarta. BPS Kabupaten Malang. (2016). Geografi. Badan Pusat Statistik Kabupaten Malang.

Cahyadi, A. (2010). Pengelolaan Kawasan Karst dan Peranannya dalam Siklus Karbon di Indonesia. Prosiding Seminar Nasional Perubahan Iklim di Indonesia. Yogyakarta : Sekolah Pasca Sarjana UGM Yogyakarta. 
(e) ISSN 2615-1847 (p) ISSN 2615-1839

Jurnal Manajemen Aset Infrastruktur \& Fasilitas - Vol. 3, No. 1, Maret 2019

Danang, S. (2008). Pengelolaan Air Pada Penampungan Air Hujan Gunung Kidul. Teknik Lingkungan, Universitas Islam Indonesia.

Haminal, M. (2013). Uji Kemampuan Slow Sand Filter dalam. Jurnal Tugas Akhir Jurusan Teknik Lingkungan, Jurusan Teknik Lingkungan, FTSP ITS, 1-5.

Hanum, F. (2002). Proses Pengolahan Air Sungai Untuk Keperluan Air Minum. Jurusan Teknik Kimia, Fakultas Teknik, Universitas Sumatera Utara. Retrieved from www.library.usu.ai.id.

Harry (2006). Racun Nitrat Nitrit. Retrieved July 27, 2017, from klikharry.files.wordpress.com

Harsoyo, B. (2010). Teknik Pemanenan Air Hujan (Rain Water Harvesting) Sebagai Alternatif Upaya Penyelamatan Sumber Daya Air Di Wilayah DKI Jakarta. Jurnal Sains \& Teknologi Modifikasi Cuaca, Vol. 11, No. 2: 23-39. BPPT

Maya, S. (2016). Tanah Kapur : Pengertian, Karakteristik dan Prosesnya. Retrieved March 27, 2017, from https://ilmugeografi.com/ilmu-bumi/tanah/tanah-kapur

Milanovic, P. (2004). Water Resources Engineering in Karst. CRC Press. Boca Raton, Florida.

PERMENKES, 2010, \& PER/ IV/ nomor 492/ MENKES/. (2010). Persyaratan Kualitas Air Minum, 1-9.

Prawita, A. \& Hadi, W. (2014). Penggunaan Unit Slow Sand Filter , Ozon Generator dan Rapid Sand Filter Skala Rumah Tangga Untuk Meningkatkan Kualitas Air Sumur Dangkal Menjadi Air Layak Minum ( Parameter Zat Organik dan Deterjen ), Vol. 3, No. 2. Jurnal Teknik ITS.

Roviq, A. (2013). Pemanenan Air Hujan Sebagai Pemenuhan Kebutuhan Air Bersih Pengungsi Bencana Banjir. Vol. 10, No. 1. Retrived from jurnal.uns.ac.id/prosbi/article/view/6316/5700

Soemitro, R.A.A. \& Suprayitno, H. (2018). "Pemikiran Awal tentang Konsep Dasar Manajemen Aset Fasilitas". Jurnal Manajemen Aset Infrastruktur \& Fasilitas, Vol. 2, Sup. 1, Juni 2018, Hal. : 1-13.

Suharto, I. (2011). Limbah Kimia Dalam Pencemaran Udara dan Air. Yogyakarta: Andi Offset.

Suprayitno, H. \& Soemitro, R.A.A. (2018). "Preliminary Reflexion on Basic Principle of Infrastructure Asset Manaement". Jurnal Manajemen Aset Infrastruktur \& Fasilitas, Vol. 2, No. 1, Maret 2018, Hal. : 1-9.

UNEP (2001). Rainwater Harvesting. UNEP International Technology Centre. Murdoch University of Western Australia.

Untari, T. (2015). Pemanfaatan Air Hujan Sebagai Air Layak Konsumsi di Kota Malang dengan Metode Modifikasi Filtrasi Sederhana. Jurusan Teknologi Hasil Pertanian, Fakultas Teknologi Pertanian, Universitas Brawijaya.

Wahid N E. (2006). Pengaruh Variasi Ketebalan Karbon Aktif Grabular (Arang Tempurung Kelapa) Terhadap Penurunan Kandungan Fe dan Mn Dalam Air Tanah. Jurusan Teknik Lingkungan, Fakultas Teknik Sipil Dan Perencanaan, UII, Jogjakarta.

Waluyo, L. (2005). Mikrobiologi Lingkungan. Retrieved from UMM Press. Malang.

Wardiha, M. W.; Prihandono, A.; \& Timur, F. (2013). Perumusan Aplikasi Alternatif Desain Penampungan Air Hujan Untuk Masyarakat. Studi Kasus: Provinsi Nusa Tenggara. Timur, 297-310. Prosiding Kolokium 2013 Puslitbang Permukiman.

White, W. B. (1988). Geomorphology and Hydrology of Karst Terrains. Oxford University Press. Oxford and New York. 
(e) ISSN 2615-1847 (p) ISSN 2615-1839

Jurnal Manajemen Aset Infrastruktur \& Fasilitas - Vol. 3, No. 1, Maret 2019 
(e) ISSN 2615-1847 (p) ISSN 2615-1839

Jurnal Manajemen Aset Infrastruktur \& Fasilitas - Vol. 3, No. 1, Maret 2019 
(e) ISSN 2615-1847 (p) ISSN 2615-1839

Jurnal Manajemen Aset Infrastruktur \& Fasilitas - Vol. 3, No. 1, Maret 2019 